\title{
Wykorzystanie właściwości allelopatycznych sorga (Sorghum bicolor) w ograniczaniu zachwaszczenia zbóż
}

\author{
The use of allelopathic properties of sorghum (Sorghum bicolor) in reducing weed \\ infestation of cereals
}

\author{
Monika Żurek $^{1 凶}$, Piotr Ochodzki ${ }^{2}$, Roman Warzecha ${ }^{1}$ \\ Instytut Hodowli i Aklimatyzacji Roślin — Państwowy Instytut Badawczy, Radzików \\ ${ }^{1}$ Zakład Genetyki i Hodowli Roślin, Pracownia Kukurydzy i Pszenżyta \\ ${ }^{2}$ Zakład Fitopatologii, Pracownia Chorób Zbóż \\ $\triangle$ e-mail: m.zurek@ihar.edu.pl
}

\begin{abstract}
Ograniczanie konkurencyjności chwastów metodami mechanicznymi (pielniki, pielenie ręczne) jest procesem czasooraz kosztochłonnym. Allelopatia odnosi się głównie do substancji chemicznych wydzielanych do podłoża, które wpływają na wzrost innych organizmów w bezpośrednim otoczeniu. Jedną z roślin o najsilniejszym potencjale allelopatycznym jest, należące do rodziny wiechlinowatych, sorgo. Celem przeprowadzonych badań było określenie potencjału allelopatycznego wybranych form (odmian) sorga oraz przydatności wyciągu wodnego z sorga (Sorghum bicolor) jako bioherbicydu w ograniczeniu zachwaszczenia w uprawie ekologicznej zbóż (kukurydzy, pszenicy, pszenżyta), w naszych warunkach klimatycznych.
\end{abstract}

\begin{abstract}
Słowa kluczowe: allelopatia, sorgo, sorgoleon, sorgaab, rolnictwo ekologiczne
Limiting the competitiveness of weeds by mechanical methods (weavers, hand weeding) is a time-consuming and cost-intensive process. Allelopathy mainly refers to chemicals released into the medium that affect the growth of other organisms in the immediate environment. One of the plants with the strongest allelopathic potential is sorghum, belonging to the family of paniculate. The aim of the research was to determine the allelopathic potential of selected sorghum forms (varieties) and the usefulness of sorghum extract as a bioherbicide in reducing weed infestation in organic cereals (maize, wheat, triticale) in our climatic conditions.
\end{abstract}

Key words: allelopathy, sorghum, sorgoleon, sorgaab, organic farming

Jednym z głównych czynników limitujących plony $\mathrm{w}$ rolnictwie ekologicznym jest problem konkurencji chwastów z roślinami uprawnymi. Ograniczanie konkurencyjności chwastów metodami mechanicznymi (pielniki, pielenie ręczne) jest procesem czaso- oraz kosztochłonnym. W doniesieniach naukowych $\mathrm{z}$ ostatnich lat, coraz większy nacisk kładzie się na wykorzystanie naturalnych, występujących w przyrodzie zależności pomiędzy roślinami uprawnymi a chwastami w celu ograniczania tych ostatnich. Jednym $\mathrm{z}$ takich zjawisk jest allelopatia. Allelopatia odnosi się głównie do substancji chemicznych wydzielanych do podłoża, które wpływają na wzrost innych organizmów $\mathrm{w}$ bezpośrednim otoczeniu. Substancje te mogą pobudzać lub hamować kiełkowanie, a także wzrost i rozwój innych gatunków roślin żyjących w bliskim sąsiedztwie lub roślin następczych. Wiele gatunków roślin posiada udokumentowane właściwości allelopatyczne, m.in.: słonecznik, gryka, orzech włoski czy żyto ozime. Jedną z roślin o najsilniejszym potencjale allelopatycznym jest, należące do rodziny wiechlinowatych (Poaceae), sorgo (Sorghum sp.). W Polsce powierzchnia uprawy sorga wynosi 20 tys. ha. W warunkach klima- tycznych Polski roślina ta jest $w$ stanie wyprodukować wysoki plon zielonej masy, nawet do 100 t/ha. Sorgo w naszym kraju jest uprawiane głównie na cele paszowe w mieszance z kukurydzą. Największe znaczenie w uprawie odgrywa sorgo cukrowe (Sorghum bicolor). Roślina ta, ze względu na niskie wymagania glebowe, a także odporność na suszę i zasolenie, może być uprawiana na słabszych glebach (Prażak, 2015). Potencjał allelopatyczny posiada zarówno nadziemna część sorga, jak również jego korzenie. Obie części zawierają jednak zupełnie inne związki które wykazują działanie allelopatyczne. Nadziemne części sorga zawierają kwasy fenolowe oraz ich pochodne aldehydowe, natomiast $\mathrm{w}$ korzeniach stwierdzono obecność sorgoleonu oraz jego analogów. $\mathrm{Z}$ danych literaturowych wynika iż sorgoleon hamuje lub ogranicza wzrost zarówno jednoliściennych, jak też dwuliściennych chwastów takich jak: psianka czarna (Solanum nigrum L), szarłat szorstki (Amaranthus retroflexus L.), chwastnica jednostronna (Echinochloa crus-galli L.) oraz miłka wonna (Eragrostis tef). Działanie fitotoksyczne sorgoleonu opiera się głównie na zahamowaniu fotosyntezy oraz syntezy karotenoidów (Dayan i in., 2010). W badaniach nad 
fitotoksycznością sorga istnieje wiele doniesień o wykorzystaniu wodnego ekstraktu z nadziemnej części tej rośliny (tzw. sorgaab), zawierającego mieszaninę kwasów fenolowych, jako środka ograniczającego zachwaszczenie. Niektóre z doniesień sugerują nawet pozytywny wpływ „sorgaabu“ na plon rośliny uprawnej w uprawie której zastosowany był oprysk tym preparatem (Alsaadawi, Dayan 2009). Celem przeprowadzonych badań było określenie potencjału allelopatycznego wybranych form (odmian) sorga oraz przydatności wyciągu wodnego $\mathrm{Z}$ sorga (Sorghum bicolor) jako bioherbicydu w ograniczeniu zachwaszczenia w uprawie ekologicznej zbóż (kukurydzy, pszenicy, pszenżyta), w naszych warunkach klimatycznych. W badaniach wykorzystano 5 odmian sorga (Sorghum bicolor) - węgierską odmianę Rona, dystrybuowaną w Polsce przez Kutnowską Hodowlę Buraka Cukrowego oraz 4 odmiany otrzymane z firmy KWS: KWS Lemnos, KWS Santos, KWS Merlin oraz KWS Titus. Do przeprowadzenie oceny wpływu wyciągów $\mathrm{Z}$ sorga na zboża i kukurydzę wykorzystano następujące odmiany: IS Questor (pszenica), Dublet (pszenżyto) oraz Skarb (kukurydza). W ocenie wpływu wyciągów z sorga na chwasty wykorzystano nasiona następujących gatunków: owies głuchy (Avena fatua L.), szarłat (Amaranthus), kąkol polny (Agrostemma githango L.) oraz komosa biała (Chenopodium album L). Ekstrakt wodny z roślin otrzymywano według standardowej procedury (Cheema $\mathrm{i}$ in., 2000), w następujący sposób: rośliny sorga po ścięciu podsuszano na słońcu przez 3-4 dni, następnie rozdrabniano mechanicznie. Tak przygotowaną sieczkę umieszczano w plastikowych beczkach, a następnie zalewano wodą $\mathrm{W}$ stosunku 1:10 (w/v). Beczki $\mathrm{z}$ maceratem trzymano w temperaturze pokojowej przez 24 godziny. Po upływie tego czasu zlewano otrzymany wyciąg (sorgaab), przepuszczając go przez sito oraz tetrę. $\mathrm{W}$ ekstraktach $\mathrm{z}$ roślin badanych odmian sorga została określona zawartość związków fenolowych. Ponadto w ekstraktach $\mathrm{z}$ korzeni określona została zawartość sorgoleonu oraz jego lipidowego analogu rezorcynolu. Zbadana została również dynamika syntezy sorgoleonu i rezorcynolu $w$ korzeniach. Zawartość tych związków została określona przy wykorzystaniu chromatografii gazowej z detekcją płomieniowojonizacyjną (GC-FID). Standard zewnętrzny sorgoleonu otrzymano od prof. Franka E. Dayana z Colorado State University. W celu określenia wpływu sorgaabu na kiełkowanie wybranych gatunków chwastów i zbóż, wysiano ich nasiona na szalkach Petriego wyłożonych bibułą. $\mathrm{Na}$ szalki aplikowano po $3 \mathrm{ml}$ wyciągu z sorga co drugi dzień. Kontrolę stanowiły szalki podlewane wodą. Szalki inkubowano w temperaturze pokojowej. W celu oceny wpływu wydzielin korzeniowych sorga na kiełkowanie, nasiona badanych gatunków wyłożono na szalki Petriego z 5.-dniowymi siewkami sorga. Według danych literaturowych (Uddin i in., 2010) maksimum wydzielania sorgoleonu siewki sorga osiągają między 5 a 10 dniem od wysiewu. Z uwagi na ten fakt ocenę kiełkowania przeprowadzono po 5. dniach od wysiewu nasion chwastów.

\section{Wyniki i wnioski}

1. Badane odmiany sorga cukrowego (Sorghum bicolor), w ekologicznych warunkach uprawy, bardzo dobrze poradziły sobie z konkurencją ze strony chwastów oraz osiągnęły plony zielonej masy na zadowalającym poziomie (średnio $65 \mathrm{t} / \mathrm{ha}$ ).

2. Poziom wydzielania sorgoleonu przez włośniki różnił się pomiędzy badanymi odmianami. Najwyższe jednostkowe stężenie tego związku na poziomie $36 \mathrm{mg} / \mathrm{g}$ s.m stwierdzono w przypadku odmiany KWS Lemnos. Produkcja sorgoleonu uzależniona była również od wieku siewek. Najwyższy poziom biosyntezy tego związku, we wszystkich odmianach sorga, występował u 5. dniowych siewek.

3. Uzyskane wyniki dotyczące wpływu sorgaabu na kiełkowanie i wzrost pszenicy, pszenżyta oraz kukurydzy, wskazują na potrzebę zachowania ostrożności w stosowaniu tego preparatu przedwschodowo, gdyż może on ograniczyć kiełkowanie oraz wzrost rośliny uprawnej. We wszystkich zastosowanych wariantach zaobserwowano, istotne statystycznie, ograniczenie wzrostu siewek.

4. W porównaniu do sorgaabu, wydzieliny korzeniowe siewek sorga w niższym stopniu wpływały na kiełkowanie oraz wzrost siewek zbóż i chwastów. Najwrażliwszym na działanie sorgoleonu, gatunkiem było pszenżyto.

5. Wszystkie badane odmiany sorga posiadają właściwości allelopatyczne, pozwalające na wykorzystanie ich do ograniczania liczebności chwastów. 


\section{Literatura}

Alsaadawi I. S., Dayan F. E 2009. Potentials and prospects of sorghum allelopathy in agroecosystems. Allelopathy Journal 24 (2): $255-270$.

Cheema Z. A., Sadiq H. M. I, Khaliq A. 2000. Efficacy of Sorgaab (Sorghum water extracts) as a natural weed inhibitor in wheat. International Journal of Agriculture and Biology 1560-8530/2000/02-1-2-144-146.
Dayan F. E., Rimando A. M., Pan Z., Baerson S. R., Gimsing A. L., Duke S. O. 2010 Sorgoleone. Phytochemistry 71: $1032-1039$.

Prażak R. 2015 Uprawa sorga cukrowego w Polsce. Wieś Jutra, 2: $46-47$.

Uddin M. R., Park K. W., Kim Y. K., Park S. U., Pyon J. Y. 2010. Enhancing sorgoleone levels in grain sorghum root exudates. J. Chem. Ecol. 36: 914 - 922. 
